\title{
Interpreting First Anti-resonance of FRA Responses Through Low Frequency Transformer Modelling
}

DOI:

10.1007/978-3-030-31676-1_92

Document Version

Accepted author manuscript

Link to publication record in Manchester Research Explorer

\section{Citation for published version (APA):}

Cheng, B., Crossley, P., Wang, Z., Jarman, P., Fieldsend-roxborough, A., \& Wilson, G. (2019). Interpreting First Anti-resonance of FRA Responses Through Low Frequency Transformer Modelling. In Proceedings of the 21st International Symposium on High Voltage Engineering (pp. 982-992). [Chapter 92] (Proceedings of the 21st International Symposium on High Voltage Engineering; Vol. 598). https://doi.org/10.1007/978-3-030-31676-1_92

Published in:

Proceedings of the 21st International Symposium on High Voltage Engineering

\section{Citing this paper}

Please note that where the full-text provided on Manchester Research Explorer is the Author Accepted Manuscript or Proof version this may differ from the final Published version. If citing, it is advised that you check and use the publisher's definitive version.

\section{General rights}

Copyright and moral rights for the publications made accessible in the Research Explorer are retained by the authors and/or other copyright owners and it is a condition of accessing publications that users recognise and abide by the legal requirements associated with these rights.

\section{Takedown policy}

If you believe that this document breaches copyright please refer to the University of Manchester's Takedown Procedures [http://man.ac.uk/04Y6Bo] or contact uml.scholarlycommunications@manchester.ac.uk providing relevant details, so we can investigate your claim.

\section{OPEN ACCESS}




\title{
INTERPRETING FIRST ANTI-RESONANCE OF FRA RESPONSES THROUGH LOW FREQUENCY TRANSFORMER MODELLING
}

\author{
Bozhi Cheng ${ }^{1}$, Peter Crossley ${ }^{1}$, Zhongdong Wang ${ }^{1 *}$, \\ Paul Jarman ${ }^{2}$, Andrew Fieldsend-Roxborough ${ }^{2}$, and Gordon Wilson ${ }^{2}$ \\ ${ }^{1}$ The University of Manchester, Manchester M13 9PL, UK \\ ${ }^{2}$ National Grid Company, Warwick CV34 6DA, UK \\ Email: *zhongdong.wang@manchester.ac.uk
}

\begin{abstract}
FRA is an effective detection method for mechanical deformation of transformer windings; however the challenge of applying the FRA technique lies in the correct interpretation of FRA measurement results. Modelling and simulation can help understand the FRA characteristics and in this respect much research work are needed especially to develop the modelling capability for three-phase three-winding autotransformers under the condition of single phase excitation such as the FRA measurement set-up. This paper is a sister paper to [8] which extends the discussion on how to interpret low frequency FRA features especially the first anti-resonance. Through our previous publication, it has become a common knowledge nowadays that the $1^{\text {st }}$ antiresonance of FRA is produced by the coupling between the core inductance and the equivalent winding capacitance, though a quantitative analysis is carried out in this paper to prescribe an analytical equation first time showing the linear composition of the equivalent winding capacitance made from winding series capacitances and inter-winding capacitances. It is necessary to understand that although shifts of resonance (and/or antiresonance) frequencies are regarded as the key indicators of winding deformation, the frequency shift, $\Delta f$, of the resonance (and/or anti-resonance) before $\left(f_{1}\right)$ and after $\left(f_{2}\right)$ the deformation, is actually not the best indicative parameter as $\Delta f$ cannot be related to the change of electrical parameters in the model, instead the ratio, $f_{2} / f_{1}$ has a well-defined quantitative linkage with the winding inductances and capacitances. It is therefore recommended to use the frequency ratio, $f_{2} / f_{1}$, of the resonance (and/or anti-resonance) before $\left(f_{1}\right)$ and after $\left(f_{2}\right)$ the deformation for FRA interpretation.
\end{abstract}

\section{Introduction}

The failure of transformers can result in safety issues and economic losses. Although FRA is widely used to detect mechanical winding deformation, the success of this technique lies in the correct interpretation of the FRA plot and up to now there is no IEC/IEEE standard for FRA interpretation although a CIGRE WG A2.53 working group is currently working towards producing a technical brochure on this respect.

Most researchers investigate the FRA characteristics in the high frequency region through experiments and/or simulation due to the FRA characteristics in this region is more winding structure related [1-6], nevertheless, the low frequency FRA feature, in the frequencies generally up to $2 \mathrm{kHz}$, associated with global parameters of a transformer, is the "grey" area where not much research attention has been paid. A measurement based approach is proposed in [7] proposed to establish a low frequency transformer model for FRA simulation studies, and the simulation results are validated through the comparison with measurement results. In [8] a $400 / 275 / 13 \mathrm{kV}$ auto-transformer is used as an example to build a low frequency first order transformer model and sensitivity studies are conducted on the influencing electrical factors on the low frequency anti-resonances and resonances. This paper is a sister paper to [8] which continue to study and discuss how to interpret the first anti-resonance of FRA responses.

\section{Simulation Model}

The transformer being modelled is a three-limb core type 1000 MVA 400/275/13 kV autotransformer. There are 3 windings per phase, i.e. series (S), common (C) and tertiary ( $\mathrm{T})$ windings. Figure 1 shows the equivalent circuit which involves both inductive and capacitive elements, where the model is a first order model where each winding is represented by one unit of global parameters, inductance and capacitance. All the representations of the symbols in the circuit can be found in Table 1, the parameters except core leg and yoke inductances are calculated based on winding geometry, while the core leg and yoke inductances are calculated based on FRA measurement results which will be discussed in Section 3.1.

In [8] it is concluded that the model can produce reasonable simulation results up to a few $\mathrm{kHz}$. The anti-resonances in the low frequency region and a typical double-peak feature of series and common 
winding FRA responses can be simulated, and sensitivity studies are implemented to identify the influence of electrical components on the FRA responses. The results show that the antiresonance of FRA response in the low frequency region is dominated by the core inductance, the double-peak feature is influenced by winding series capacitance and air-core inductances, and the interwinding capacitances can affect both the first anti-resonance and the double-peak feature sensitively. While the FRA characteristics in the high frequency region cannot be reflected due to the over-simplicity of the first order model [8].

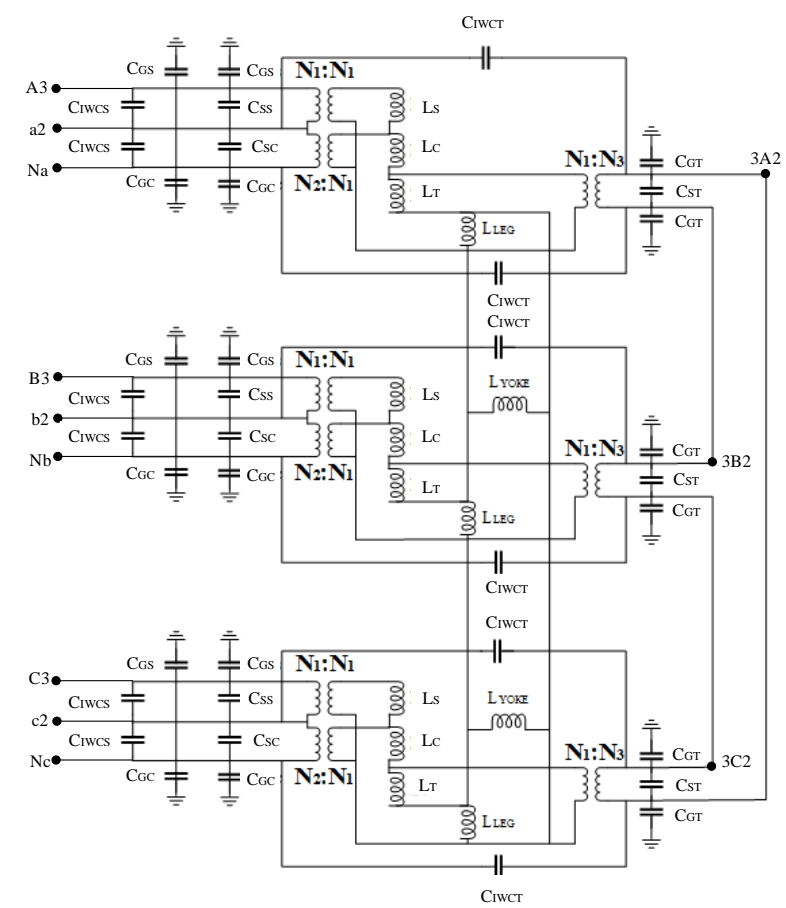

Figure 1: Equivalent circuit of 400/275/13 kV autotransformer

Table 1: Electrical parameters in the model

\begin{tabular}{|c|c|}
\hline Parameters & Values \\
\hline Ground capacitance of series winding $\mathrm{C}_{\mathrm{GS}}$ & $241.08 \mathrm{pF}$ \\
\hline Series capacitance of series winding $\mathrm{C}_{\mathrm{SS}}$ & $1603.86 \mathrm{pF}$ \\
\hline Ground capacitance of common winding $\mathrm{C}_{\mathrm{GC}}$ & $38.5 \mathrm{pF}$ \\
\hline Series capacitance of common winding $\mathrm{C}_{\mathrm{SC}}$ & $30.21 \mathrm{pF}$ \\
\hline $\begin{array}{c}\text { Interwinding capacitance between common } \\
\text { and series windings } \mathrm{C}_{\mathrm{IWCS}}\end{array}$ & $1495.57 \mathrm{pF}$ \\
\hline Ground capacitance of tertiary winding $\mathrm{C}_{\mathrm{GT}}$ & $2820.05 \mathrm{pF}$ \\
\hline Series capacitance of tertiary winding $\mathrm{C}_{\mathrm{ST}}$ & $5.67 \mathrm{pF}$ \\
\hline $\begin{array}{c}\text { Interwinding capacitance between common } \\
\text { and tertiary windings } \mathrm{C}_{\mathrm{IWCT}}\end{array}$ & $772.45 \mathrm{pF}$ \\
\hline Air-core inductance of series winding $\mathrm{L}_{\mathrm{S}}$ & $159.2 \mathrm{mH}$ \\
\hline Air-core inductance of common winding $\mathrm{L}_{\mathrm{C}}$ & $83.34 \mathrm{mH}$ \\
\hline Air-core inductance of tertiary winding $\mathrm{L}_{\mathrm{T}}$ & $438.51 \mathrm{mH}$ \\
\hline Core leg inductance $\mathrm{L}_{\mathrm{LEG}}$ & $13.43 \mathrm{H}$ \\
\hline Core yoke inductance $\mathrm{L}_{\mathrm{YOKE}}$ & $12.61 \mathrm{H}$ \\
\hline $\mathrm{N}_{1}: \mathrm{N}_{2}$ & $125: 275$ \\
\hline $\mathrm{N}_{1}: \mathrm{N}_{3}$ & $125 / \sqrt{3}: 13$ \\
\hline
\end{tabular} \\ Interpretation of First Anti-resonance}

\subsection{Core inductance calculation based on FRA}

In [7], a group of special winding terminal tests are performed to obtain the electrical parameters for the transformer model. Some of the parameters identified by the special terminal tests may be found in the factory test reports and capacitance/tangent delta test report; measurements of core leg and yoke inductances are special, and they can be identified also by an alternative approach, demonstrated in this section. Based on three phases FRA measurement data at low frequencies, core leg and yoke inductances can be calculated and no extra terminal tests are required. In the core dominated low frequency region of FRA response, the magnitude decreases as $20 \mathrm{~dB}$ per decade, and the equivalent circuit of FRA end-to-end measurement can be regarded as a purely inductance with a $50 \Omega$ in series connection, shown in Figure 2.

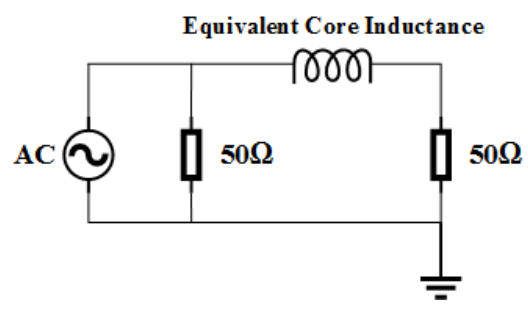

Figure 2: Equivalent circuit of FRA measurement in the low frequency region

The ratio of terminal voltages can be calculated by equation (1).

$$
A=20 \log _{10}\left(\left|\frac{V_{\text {out }}}{V_{\text {in }}}\right|\right)
$$

Where $A$ is the FRA magnitude data $(\mathrm{dB}), \mathrm{V}_{\text {in }}$ and $\mathrm{V}_{\text {out }}$ are the voltages measured at the input and output terminals of a winding. The equivalent core inductances can be calculated from $A$ and $B$ phase FRA measurement data as they are different combinations of core leg and yoke inductances, given as:

$$
\begin{gathered}
\mathrm{L}_{\mathrm{eA}}=\left(\mathrm{L}_{\mathrm{LEG}} / / \mathrm{L}_{\mathrm{YOKE}}+\mathrm{L}_{\mathrm{YOKE}}\right) / /\left(\mathrm{L}_{\mathrm{LEG}} / / \mathrm{L}_{\mathrm{YOKE}}\right) \\
\mathrm{L}_{\mathrm{eB}}=\left(\mathrm{L}_{\mathrm{LEG}} / / \mathrm{L}_{\mathrm{YOKE}}+\mathrm{L}_{\mathrm{LEG}} / / \mathrm{L}_{\mathrm{YOKE}}\right) / / \mathrm{L}_{\mathrm{LEG}}
\end{gathered}
$$

Where $L_{e A}$ is equivalent core inductance calculated based on $A$ phase FRA measurement data, equivalent core inductance of $C$ phase has the same expression to A phase, $\mathrm{L}_{\mathrm{eB}}$ is equivalent core inductance calculated based on $B$ phase FRA measurement data.

$\mathrm{L}_{\mathrm{eA}}$ and $\mathrm{L}_{\mathrm{eB}}$ are calculated based on FRA measurement data between $5 \mathrm{~Hz}$ and $60 \mathrm{~Hz}$ as 
higher than $60 \mathrm{~Hz}$ the capacitive elements start to influence the FRA response, resulting in the FRA magnitude decreases more than $20 \mathrm{~dB}$ per decade. The mean values of equivalent core inductances seen from $A$ and $B$ phase windings are calculated, Table 2 gives the inductance calculation results from $A$ and $B$ phase winding FRA measurement data. It should be mentioned that $\mathrm{L}_{\mathrm{LEG}}$ and $\mathrm{L}_{\mathrm{YOKE}}$ of three windings (Series, Common and Tertiary) follows exactly the relationship of the ratio of turn number squared.

Table 2 Equivalent core inductance, $\mathrm{L}_{\mathrm{LEG}}$ and $\mathrm{L}_{\text {YOKE }}$ seen at three winding terminals

\begin{tabular}{|c|c|c|c|}
\hline Parameters & Series & Common & Tertiary \\
\hline Mean $\mathrm{L}_{\mathrm{eA}}$ & $4.85 \mathrm{H}$ & $23.56 \mathrm{H}$ & $158 \mathrm{mH}$ \\
\hline Mean $\mathrm{L}_{\mathrm{eB}}$ & $6.61 \mathrm{H}$ & $31.97 \mathrm{H}$ & $215 \mathrm{mH}$ \\
\hline $\mathrm{L}_{\mathrm{LEG}}$ & $13.43 \mathrm{H}$ & $64.82 \mathrm{H}$ & $438 \mathrm{mH}$ \\
\hline $\mathrm{L}_{\mathrm{YOKE}}$ & $12.61 \mathrm{H}$ & $61.50 \mathrm{H}$ & $411 \mathrm{mH}$ \\
\hline
\end{tabular}

Although the core and air core inductances plugged into the model are the values seen from series winding side, with the involvement of ideal transformers, the model is capable to perform FRA simulation on either common or tertiary winding terminals without changing the values of any inductive elements.

The model has been validated in [8] to produce reasonable low frequency FRA characteristics, as compared with measurement results. Next section will be based on the model and conduct sensitivity simulation studies to investigate the frequency of the first anti-resonance and its influencing factors.

\subsection{Composition of equivalent winding capacitance $C_{e}$ seen at winding terminal}

Based on the knowledge of how the first antiresonance of FRA response is produced [8], the frequency of the first anti-resonance can be expressed by equation (4).

$$
\mathrm{f}=\frac{1}{2 \pi \sqrt{\mathrm{LC}_{\mathrm{e}}}}
$$

Where $f$ is the frequency of the first anti-resonance, $L$ is the equivalent core inductance combined by $\mathrm{L}_{\mathrm{LEG}}$ and $\mathrm{L}_{Y O K E}, \mathrm{C}_{\mathrm{e}}$ is the equivalent winding capacitance seen as a global parameter at the winding terminal, which is believed to be composed of all geometric winding capacitances.

To quantify the influence of winding capacitances on the first anti-resonance, the relationship between $\mathrm{C}_{\mathrm{e}}$ and winding capacitances is required. In this section, sensitivity studies on the contribution from individual winding capacitance to $\mathrm{C}_{\mathrm{e}}$ is implemented. Three windings of $\mathrm{B}$ phase are tested individually, $\mathrm{L}_{\mathrm{LEG}}$ and $\mathrm{L}_{\mathrm{YOKE}}$ are not changed, the value of each individual winding capacitance is changed from $10 \%, 100 \%, 200 \%$, ... to $600 \%$ of the original value. To calculate the value of $\mathrm{C}_{\mathrm{e}}$ in each sensitivity study, the equivalent core inductances of $\mathrm{B}$ phase series, common and tertiary windings are used according to Table 2, then the first anti-resonance frequency is identified from the FRA response and equation (4) is used to calculate $C_{e}$. The baseline of $C_{e}$ seen from series, common and tertiary windings, are equal to 25556 pF, 4034 pF and 826990 pF respectively.

After the sensitivity studies, the relationship between $\mathrm{C}_{\mathrm{e}}$ at the first anti-resonance and the winding capacitances for $B$ phase windings are shown in Figure 3, Figure 4 and Figure 5 respectively.

It is found that no matter which winding is tested, the winding series capacitances and interwinding capacitances always have a linear relationship with $\mathrm{C}_{\mathrm{e}}$, and $\mathrm{C}_{\mathrm{IWCS}}$ contributes most to $\mathrm{C}_{\mathrm{e}}$ among all the capacitive elements.

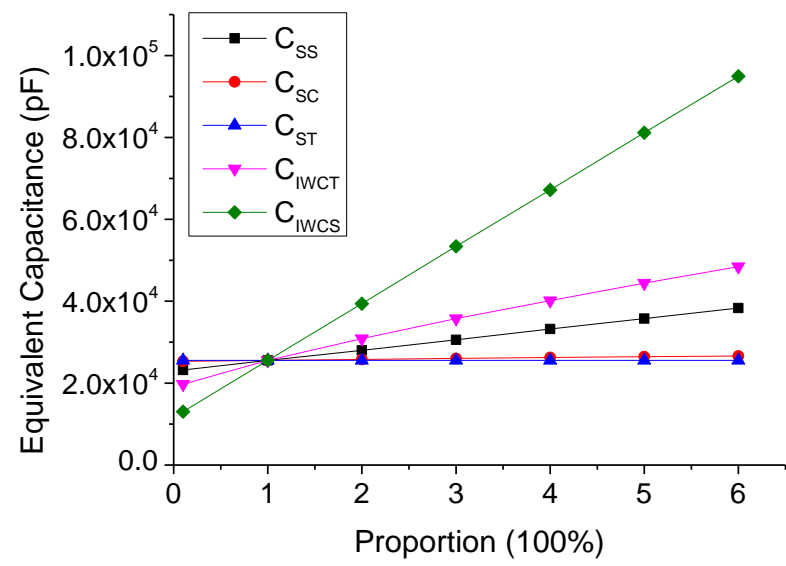

Figure $3 \mathrm{C}_{\mathrm{e}}$ for series winding

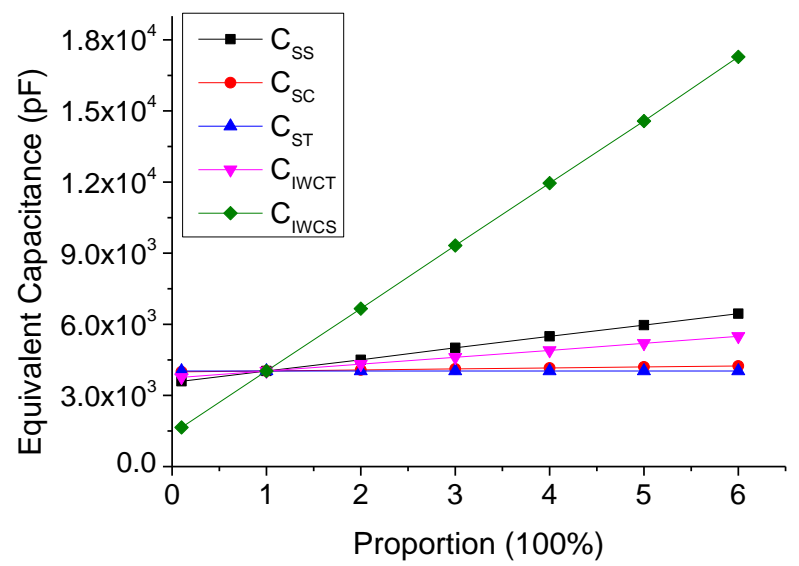

Figure $4 \mathrm{C}_{\mathrm{e}}$ for common winding 


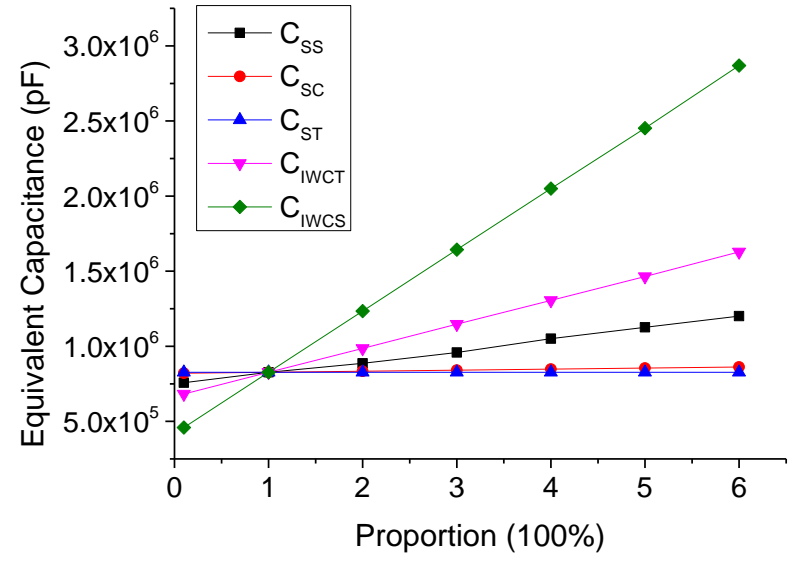

Figure $5 \mathrm{C}_{\mathrm{e}}$ for tertiary winding

The influence of $\mathrm{C}_{\text {IWCS }}$ can even transfer to the FRA response of tertiary winding, consequently explains the result that $\mathrm{C}_{\mathrm{IWCS}}$ has the most sensitive influence on the $1^{\text {st }}$ anti-resonance of $B$ phase winding FRA responses [8]. For series and tertiary windings, $\mathrm{C}_{\mathrm{IWCT}}$ takes the secondary status. For common winding, $\mathrm{C}_{\mathrm{SS}}$ ranks only second to $\mathrm{C}_{\mathrm{IWCS}}$, on the other hand, the series capacitances of common and tertiary windings have minor contribution to $\mathrm{C}_{\mathrm{e}}$ because they are too small when compare to other capacitive elements.

Through the linear regression method, the expressions of equivalent capacitance $C_{e}$ for $B$ phase windings are calculated and shown as equation (5), (6) and (7) respectively, the unit for the variables in three equations is $\mathrm{pF}, \mathrm{C}_{\mathrm{ST}}$ is neglected in the equations since it is so small that even $600 \% \mathrm{C}_{\mathrm{ST}}$ can hardly shift the first antiresonance in any sensitivity study case (frequency resolution is $1 \mathrm{~Hz}$ ), in addition, for the constants $(1715,584$ and $207590 \mathrm{pF})$ in the equations, it is believed that they represent the effect of winding ground capacitances.

$$
\begin{gathered}
\mathrm{C}_{\mathrm{es}}=1.59 \mathrm{C}_{\mathrm{SS}}+7.46 \mathrm{C}_{\mathrm{SC}}+3.11 \mathrm{C}_{\mathrm{IWCT}}+4.64 \mathrm{C}_{\mathrm{IWCS}}+1715 \\
\mathrm{C}_{\mathrm{ec}}=0.3 \mathrm{C}_{\mathrm{SS}}+1.38 \mathrm{C}_{\mathrm{SC}}+0.18 \mathrm{C}_{\mathrm{IWCT}}+0.88 \mathrm{C}_{\mathrm{IWCS}}+584 \\
\mathrm{C}_{\mathrm{et}}=47 \mathrm{C}_{\mathrm{SS}}+233 \mathrm{C}_{\mathrm{SC}}+103.6 \mathrm{C}_{\mathrm{IWCT}}+136 \mathrm{C}_{\mathrm{IWCS}}+207590
\end{gathered}
$$

With the relationship developed between $\mathrm{C}_{\mathrm{e}}$ and other geometric winding capacitances, it is now feasible to demonstrate that the frequency of the first anti-resonance can be represented by electrical parameters in the model.

\subsection{Discussion on deformation indicative parameter which can link with change of electrical parameter in equivalent circuit}

The essence of FRA interpretation is to quantify the relationship among winding geometry, electrical parameters of the model and the FRA plot, or in another word, the change of winding geometric dimension, electrical parameters and the shift of resonance or anti-resonance frequencies of the FRA response.

Generally, the frequency shifting $(\Delta \mathfrak{f})$ was used to describe and reflect the degree of deformation, however in this section, a proposal is made, based on this study of the first anti-resonance, to use instead the ratio expression of frequency before $\left(f_{1}\right)$ and after $\left(f_{2}\right)$ the deformation to build a direct linkage with the change of electrical parameters in the equivalent circuit.

Based on (4), it is possible to link the shift of frequency of the first anti-resonance with the change of electrical parameters of the equivalent circuit as expressed by equation (5).

$$
\frac{\mathrm{f}_{2}}{\mathrm{f}_{1}}=\frac{\sqrt{\mathrm{L}_{1} \mathrm{C}_{\mathrm{e} 1}}}{\sqrt{\mathrm{L}_{2} \mathrm{C}_{\mathrm{e} 2}}}
$$

Where $f_{1}$ represents the frequency of baseline, $f_{2}$ represents the frequency after deformation and its associated change of electrical parameters, $\mathrm{L}_{1}, \mathrm{C}_{\mathrm{e} 1}$ and $\mathrm{L}_{2}, \mathrm{C}_{\mathrm{e} 2}$ represent the electrical parameters before and after the deformation.

\subsubsection{Demonstration case 1: core inductance}

To verify the effectiveness of expression (5) and the influence of core inductance on the first antiresonance, the sensitivity study results on the core inductance are extracted from [8].

In reality, the core inductance can be changed due to winding short circuit fault or during the transformer short circuit test. In this sensitivity study case, $\mathrm{L}_{\mathrm{LEG}}$ and $\mathrm{L}_{\mathrm{YOKE}}$ are changed to $50 \%$ lower and then $200 \%$ higher. Following (5), when $\mathrm{L}_{\mathrm{LEG}}$ and $\mathrm{L}_{\mathrm{YOKE}}$ are reduced by $50 \%$, the ratio $\mathrm{f}_{2} / \mathrm{f}_{1}$ should be equal to 1.414 and when $\mathrm{L}_{\mathrm{LEG}}$ and $\mathrm{L}_{\mathrm{YOKE}}$ are increased by $200 \%$, the ratio $\mathrm{f}_{2} / \mathrm{f}_{1}$ should be equal to $\mathbf{0 . 7 0 7}$. The comparison on the effectiveness of $\Delta f$ and the ratio, $f_{2} / f_{1}$ to be related to the change of core inductance is presented in Table 3.

Table 3 Frequency ratio and $\Delta f$

(a) Series winding (S) results

\begin{tabular}{|c|c|c|c|}
\hline Case & Fre (Hz) & $\mathbf{f}_{\mathbf{2}} / \mathbf{f}_{\mathbf{1}}$ & $\boldsymbol{\Delta} \mathbf{f}$ \\
\hline Baseline & $386 \mathrm{~Hz}$ & - & - \\
\hline $\begin{array}{c}50 \% \text { of } \mathrm{L}_{\mathrm{LEG}} \\
\text { and } \mathrm{L}_{\mathrm{Y} \text { KE }}\end{array}$ & $533 \mathrm{~Hz}$ & $\mathbf{1 . 3 8 1}$ & $147 \mathrm{~Hz}$ \\
\hline $\begin{array}{c}200 \% \text { of } \mathrm{L}_{\mathrm{LEG}} \\
\text { and } \mathrm{L}_{\mathrm{YOKE}}\end{array}$ & $276 \mathrm{~Hz}$ & $\mathbf{0 . 7 1 5}$ & $-110 \mathrm{~Hz}$ \\
\hline
\end{tabular}


(b) Common winding $(\mathrm{C})$ results

\begin{tabular}{|c|c|c|c|}
\hline Case & Fre (Hz) & $\mathbf{f}_{\mathbf{2}} / \mathbf{f}_{\mathbf{1}}$ & $\mathbf{\Delta f}$ \\
\hline Baseline & $424 \mathrm{~Hz}$ & - & - \\
\hline $\begin{array}{c}50 \% \text { of } \mathrm{L}_{\mathrm{LEG}} \\
\text { and } \mathrm{L}_{\mathrm{YOKE}}\end{array}$ & $588 \mathrm{~Hz}$ & $\mathbf{1 . 3 8 7}$ & $164 \mathrm{~Hz}$ \\
\hline $\begin{array}{c}200 \% \text { of } \mathrm{L}_{\mathrm{LEG}} \\
\text { and } \mathrm{L}_{\text {YOKE }}\end{array}$ & $318 \mathrm{~Hz}$ & $\mathbf{0 . 7 5 0}$ & $-106 \mathrm{~Hz}$ \\
\hline
\end{tabular}

(c) Tertiary winding ( $\mathrm{T}$ ) results

\begin{tabular}{|c|c|c|c|}
\hline Case & Fre (Hz) & $\mathbf{f}_{\mathbf{2}} / \mathbf{f}_{\mathbf{1}}$ & $\boldsymbol{\Delta} \mathbf{f}$ \\
\hline Baseline & $367 \mathrm{~Hz}$ & - & - \\
\hline $\begin{array}{c}50 \% \text { of } \mathrm{L}_{\mathrm{LEG}} \\
\text { and } \mathrm{L}_{\mathrm{YOKE}}\end{array}$ & $508 \mathrm{~Hz}$ & $\mathbf{1 . 3 8 4}$ & $141 \mathrm{~Hz}$ \\
\hline $\begin{array}{c}200 \% \text { of } \mathrm{L}_{\mathrm{LEG}} \\
\text { and } \mathrm{L}_{\mathrm{YOKE}}\end{array}$ & $277 \mathrm{~Hz}$ & $\mathbf{0 . 7 5 5}$ & $-90 \mathrm{~Hz}$ \\
\hline
\end{tabular}

According to the calculation results shown in , it can be concluded that equation (5) can successfully link the change of core inductance to the frequency ratio of $f_{2} / f_{1}$. As $f_{3} / f_{1}$ based on the simulated FRA plots are very close to the calculated value of $\mathbf{1 . 4 1 4}$ and $\mathbf{0 . 7 0 7}$, although slight deviations are found due to that the frequency resolution $(1 \mathrm{~Hz})$ is not small enough. On the other hand, using $\Delta f$ cannot give an intuitive impression that how the core inductance is changed.

\subsubsection{Demonstration case 2: winding capacitance}

To verify the expressions of $C_{e}$ for different $B$ phase windings, the sensitivity study results of $B$ phase series winding in [8] are extracted, and new sensitivity studies of B phase common and tertiary windings are conducted.

In the case of capacitive elements sensitivity studies, no inductive elements are changed, each individual winding capacitance is doubled, the ratios of frequencies $\left(f_{2} / f_{1}\right)$ at the first antiresonance are calculated based on FRA simulation results, and ratios of the square root of $\mathrm{C}_{\mathrm{e}}\left(\sqrt{\mathrm{C}_{\mathrm{e} 1}}\right)$ $\sqrt{\mathrm{C}_{\mathrm{e} 2}}$ ) are calculated by equation (5), (6) and (7). The frequency of $1^{\text {st }}$ anti-resonance, the frequency ratio, the ratio of $\sqrt{\mathrm{C}_{\mathrm{e} 1}} / \sqrt{\mathrm{C}_{\mathrm{e} 2}}$ and the frequency shift $\Delta \mathrm{f}$ are calculated and presented in Table 4.

Using the expressions of $\mathrm{C}_{\mathrm{e}}$ derived in section 3.2, doubled individual geometric winding capacitance may only bring a small percentage change to $\mathrm{C}_{\mathrm{e}}$. The frequency ratios $\left(f_{2} / f_{1}\right)$ can be extracted from FRA plots, which are very similar to the ratio of the square root of $C_{e}\left(\sqrt{C_{e}} / \sqrt{C_{e 2}}\right)$ before and after the change of capacitance for all cases. The sensitive influence of $\mathrm{C}_{\mathrm{IWCS}}$ on $\mathrm{C}_{\mathrm{e}}$ also provide quantitative explanation for the results in [8]. On the other hand, $\Delta f$ cannot be related to the change of the electrical parameters.
Table 4 Frequency ratio $f_{2} / f_{1}$ and $\Delta f$ caused by geometric winding capacitances

(a) Series winding results

\begin{tabular}{|c|c|c|c|c|c|}
\hline Case & $\begin{array}{c}\text { Frequency } \\
(\mathbf{H z})\end{array}$ & $\begin{array}{c}\mathbf{C}_{\mathbf{e}} \\
(\mathbf{p F})\end{array}$ & $\mathbf{f}_{\mathbf{2}} / \mathbf{f}_{\mathbf{1}}$ & $\frac{\sqrt{\mathbf{C}_{\mathbf{e} 1}}}{\sqrt{\mathbf{C}_{\mathbf{e} 2}}}$ & $\begin{array}{c}\mathbf{\Delta f} \\
(\mathbf{H z})\end{array}$ \\
\hline Baseline & 386 & 25556 & - & - & - \\
\hline 2 times $\mathrm{C}_{\mathrm{SS}}$ & 370 & 28022 & $\mathbf{0 . 9 5 9}$ & $\mathbf{0 . 9 5 3}$ & -16 \\
\hline 2 times $\mathrm{C}_{\mathrm{SC}}$ & 385 & 25793 & $\mathbf{0 . 9 9 7}$ & $\mathbf{0 . 9 9 6}$ & -1 \\
\hline 2 times $\mathrm{C}_{\mathrm{IWCT}}$ & 352 & 30875 & $\mathbf{0 . 9 1 2}$ & $\mathbf{0 . 9 1 7}$ & -34 \\
\hline 2 times $\mathrm{C}_{\mathrm{IWCS}}$ & 312 & 39392 & $\mathbf{0 . 8 0 8}$ & $\mathbf{0 . 8 0 5}$ & -74 \\
\hline
\end{tabular}

(b) Common winding results

\begin{tabular}{|c|c|c|c|c|c|}
\hline Case & $\begin{array}{c}\text { Frequency } \\
\mathbf{( H z )}\end{array}$ & $\begin{array}{c}\mathbf{C}_{\mathbf{e}} \\
(\mathbf{p F})\end{array}$ & $\mathbf{f}_{\mathbf{2}} / \mathbf{f}_{\mathbf{1}}$ & $\frac{\sqrt{\mathrm{C}_{\mathrm{e} 1}}}{\sqrt{\mathrm{C}_{\mathrm{e} 2}}}$ & $\begin{array}{c}\mathbf{\Delta f} \\
\mathbf{( H z )}\end{array}$ \\
\hline Baseline & $424 \mathrm{~Hz}$ & 4034 & - & - & - \\
\hline 2 times $\mathrm{C}_{\mathrm{SS}}$ & $403 \mathrm{~Hz}$ & 4505 & $\mathbf{0 . 9 5 1}$ & $\mathbf{0 . 9 4 5}$ & -21 \\
\hline 2 times $\mathrm{C}_{\mathrm{SC}}$ & $423 \mathrm{~Hz}$ & 4076 & $\mathbf{0 . 9 9 8}$ & $\mathbf{0 . 9 9 5}$ & -1 \\
\hline 2 times $\mathrm{C}_{\mathrm{IWCT}}$ & $411 \mathrm{~Hz}$ & 4323 & $\mathbf{0 . 9 6 9}$ & $\mathbf{0 . 9 6 7}$ & -13 \\
\hline 2 times $\mathrm{C}_{\mathrm{IWCS}}$ & $331 \mathrm{~Hz}$ & 6664 & $\mathbf{0 . 7 8 1}$ & $\mathbf{0 . 7 7 7}$ & -93 \\
\hline
\end{tabular}

(c) Tertiary winding results

\begin{tabular}{|c|c|c|c|c|c|}
\hline Case & $\begin{array}{c}\text { Frequency } \\
\mathbf{( H z )}\end{array}$ & $\begin{array}{c}\mathbf{C}_{\mathbf{e}} \\
(\mathbf{n F})\end{array}$ & $\mathbf{f}_{\mathbf{2}} / \mathbf{f}_{\mathbf{1}}$ & $\frac{\sqrt{\mathrm{C}_{\mathrm{e}}}}{\sqrt{\mathrm{C}_{\mathrm{e} 2}}}$ & $\begin{array}{c}\mathbf{\Delta f} \\
(\mathbf{H z})\end{array}$ \\
\hline Baseline & $367 \mathrm{~Hz}$ & 826.99 & - & - & - \\
\hline 2 times $\mathrm{C}_{\mathrm{SS}}$ & $356 \mathrm{~Hz}$ & 886.5 & $\mathbf{0 . 9 7 0}$ & $\mathbf{0 . 9 5 9}$ & -11 \\
\hline 2 times $\mathrm{C}_{\mathrm{SC}}$ & $367 \mathrm{~Hz}$ & 834.03 & $\mathbf{1}$ & $\mathbf{0 . 9 9 6}$ & 0 \\
\hline 2 times $\mathrm{C}_{\mathrm{IWCT}}$ & $338 \mathrm{~Hz}$ & 985.65 & $\mathbf{0 . 9 2 1}$ & $\mathbf{0 . 9 1 8}$ & -29 \\
\hline 2 times $\mathrm{C}_{\mathrm{IWCS}}$ & $302 \mathrm{~Hz}$ & 1234.6 & $\mathbf{0 . 8 2 3}$ & $\mathbf{0 . 8 2 4}$ & -65 \\
\hline
\end{tabular}

With the works presented in section 3 , an interpretation procedure towards the frequency shift of first anti-resonance can then be summarized as follows:

1) Calculating the equivalent core inductances of baseline FRA $\left(\mathrm{L}_{1}\right)$ and diagnostic FRA $\left(\mathrm{L}_{2}\right)$ based on low frequency FRA data, by comparing the calculation results, the variation of core inductance can be quantified.

2) Calculating the ratio of frequencies $\left(f_{2} / f_{1}\right)$ and $\sqrt{\mathrm{L}_{1}} / \sqrt{\mathrm{L}_{2}}$ to indicate if winding capacitances are also changed.

3 ) In the case of winding capacitance being modified, the equation (5), (6) and (7) can then be used to further discuss the variation of capacitive elements.

\section{Conclusions}

In this paper, a first order transformer model is established to discuss the FRA characteristics in 
the low frequency region. Special attention is paid to the first anti-resonance of FRA response, with the knowledge that the first anti-resonance is created by the resonant coupling between core inductance and equivalent winding capacitance. A quantitative analysis is carried out and for the first time a linear composition of the equivalent winding capacitance made from winding series capacitances and interwinding capacitances is revealed, consequently, the linkage of the first antiresonance and the electrical components of the equivalent circuit, is proposed.

In the respect of diagnosis, frequency shifts of the resonance and/or anti-resonance, are generally regarded as the key indicators of winding deformation. Under a much more severe situation, creation of new or disappearance of old resonances can also occur. In this paper, it is suggested that the frequency shift $\Delta f$ is not able to intuitively reflect the change of electrical parameters; alternatively the frequency ratio $\left(f_{2} / f_{1}\right)$ can better represent the quantitative change of electrical parameters in the equivalent circuit.

\section{REFERENCES}

[1] J. F. Jiang, L. J. Zhou, S. B. Gao, W. Li, and D. Y. Wang, "Frequency Response Features of Axial Displacement Winding Faults in Autotransformers With Split Windings,", IEEE Transactions on Power Delivery, vol. 33, no. 4, pp. 1699-1706, Aug 2018.

[2] M. H. Samimi, S. Tenbohlen, A. A. S. Akmal, and $\mathrm{H}$. Mohseni, "Dismissing Uncertainties in the FRA Interpretation," IEEE Transactions on Power Delivery, vol. 33, no. 4, pp. 2041-2043, Aug 2018.

[3] Z. D. Wang, J. Li, and D. M. Sofian, "Interpretation of Transformer FRA ResponsesPart I: Influence of Winding Structure," IEEE Transactions on Power Delivery, vol. 24, no. 2, pp. 703-710, Apr 2009.

[4] D. M. Sofian, Z. D. Wang, and J. Li, "Interpretation of Transformer FRA Responses - Part II: Influence of Transformer Structure," IEEE Transactions on Power Delivery, vol. 25, no. 4, pp. 2582-2589, Oct 2010.

[5] N. Hashemnia, A. Abu-Siada, and S. Islam, "Improved Power Transformer Winding Fault Detection using FRA Diagnostics - Part 1: Axial Displacement Simulation," IEEE Transactions on Dielectrics and Electrical Insulation, vol. 22, no. 1, pp. 556-563, Feb 2015.

[6] N. Hashemnia, A. Abu-Siada, and S. Islam, "Improved Power Transformer Winding Fault Detection using FRA Diagnostics - Part 2: Radial Deformation Simulation," IEEE Transactions on Dielectrics and Electrical Insulation, vol. 22, no. 1, pp. 564-570, Feb 2015.
[7] D. A. K. Pham, T. M. T. Pham, H. Borsi, and E. Gockenbach, "A new method for purposes of failure diagnostics and FRA interpretation applicable to power transformers," IEEE Transactions on Dielectrics and Electrical Insulation, vol. 20, no. 6, pp. 2026-2034, 2013.

[8] B. Cheng, P. Crossley, Z. D. Wang, P. Jarman and $A$. Fieldsend-Roxborough, "Interpretation of FRA Results through Low Frequency Transformer Modelling," IEEE $2^{\text {nd }}$ Internation Conference on Electrical Materials and Power Equipment, Guangzhou, China, Apr 2019. 